\title{
Internationalization of Enterprises in Yunnan Province and Opportunities from "One Belt and One Road” Building
}

\author{
Jing Lv \\ Yunnan University of Finance and Economics \\ International Business School \\ Kunming, China \\ 1114011843@qq.com
}

Ziqi Liu

Yunnan University of Finance and Economics International Business School

\author{
Honglie Zhang* \\ Yunnan University of Finance and Economics \\ International Business School \\ Kunming, China \\ yufehelen@126.com \\ Kunming, China \\ 892172663@qq.com
}

\begin{abstract}
The "One Belt and One Road" initiative has provided good international public opinion, policy environment and trade facilities for the internationalization of Chinese enterprises. Under this background, Yunnan enterprises, as the carrier of provincial economic development, should also actively respond to the call, relying on Yunnan's unique geographical advantages, resource advantages, historical and realistic foundations to solve its own industrial problems and use good opportunities to open up an international path. However, due to various reasons, the internationalization of Yunnan enterprises has not reached the expected level. This paper elaborates the current situation of the internationalization of Yunnan enterprises, analyzes the obstacles and difficulties encountered in the process of internationalization, finally proposes measures and suggestions for Yunnan enterprises to grasp the "One Belt and One Road" opportunity under policy convenience and its own advantages.
\end{abstract}

Keywords-internationalization of enterprises; "One Belt and One Road"; construction opportunities

\section{INTRODUCTION}

The "One Belt and One Road" initiative is a major strategic plan that complies with China's economic development and the new situation of world economic development. Since its introduction in 2013, it has greatly promoted the economic development along the route. As of 2016, the trade volume of countries along the route has reached $21.7 \%$ of the world's total. With the key position in southwestern area, Yunnan province boasts unique geographical advantages, resource advantages, and historical and practical foundations. It is the gateway of the economic corridor between China, Bangladesh, India, Myanmar, and the China-Indochina Peninsula. It should be positioned accurately under the premise of solving its own industrial development issues, take on the "Belt and Road" ride. For the blending in the "Belt and Road" initiative and developing with it, proposed that the construction of a radiation center is to give full play to its advantages in location, resources, humanities, etc., and persist in coordinating domestic and provincial development.

The enterprise is the microscopic subject that promotes the economic development of Yunnan. In 2016, the total import and export volume of Yunnan Province was US\$19.99 billion, accounting for $9.02 \%$ of the province's annual GDP. As an important participant in promoting Yunnan's integration into the "Belt and Road" initiative, it should actively expand Overseas business realizes the internationalization of the company. The realization of the internationalization of enterprises in Yunnan Province is not only conducive to the growth of the company itself, but also to the economic development of Yunnan Province. The construction of the "One Belt and One Road" is exactly a good opportunity for Yunnan enterprises to carry out internationalization. However, under this strategic dividend, the level of internationalization of Yunnan enterprises is still at a relatively low level. Frontier openness advantage is insufficient, and the advantages of location and resources are not clearly demonstrated, the proportion of the country's total investment in foreign direct investment, foreign project contracting, and foreign labor cooperation is not high. There are many reasons for this, both inside and outside, and it is worth further discussion.

\section{STATUS QUO OF INTERNATIONALIZATION OF YUNNAN ENTERPRISES}

Generally speaking, the internationalization of Yunnan enterprises has developed in terms of foreign direct investment, foreign project contracting, and foreign labor cooperation, but the proportion of the country's total is still relatively low. Under the "One Belt, One Road" initiative policy support and its own advantages, it should have a higher level of internationalization.

*Corresponding author 


\section{A. Foreign Direct Investment}

In 2017, Yunnan Province approved a total of 48 foreigninvested enterprises, and the actual foreign investment was US $\$ 1.82$ billion, an increase of $13.0 \%$ over the same period of last year [1]. As of December 2017, the number of overseas investment companies (institutions) in Yunnan Province has reached 728, and the actual foreign investment has reached US\$9.221 billion, but it only accounts for only $1.52 \%$ of the country's total investment [2].

\section{B. Contracting for Foreign Projects.}

In 2017, Yunnan Province signed a total of 99 foreign contracted projects newly. The value of newly signed contracts was 1.363 billion U.S. dollars, a year-on-year decrease of $28.99 \%$, and the sales volume was 1.703 billion U.S. dollars, a year-on-year decrease of $33.88 \%$. China's foreign contracted projects completed a turnover of 168.59 billion U.S. dollars, an increase of $5.8 \%$ year-on-year; newly signed contracts amounted to 265.28 billion U.S. dollars, an increase of $8.7 \%$ year-on-year [3]. The amount of newly signed contracts in Yunnan Province only accounted for $0.51 \%$ of the national share. The turnover of foreign contracted projects only accounted for $1.01 \%$ of the country's total. Major companies include China Power Construction Group Kunming Survey and Design Institute, China Southern Power Grid Yunnan International Co., Ltd., and Yunnan Construction Engineering Group Co., Ltd.

\section{Foreign Labor Cooperation.}

As of the end of December 2017, Yunnan Province had accumulatively distributed 119,037 laborers of various types, and there were 10,665 foreigners at the end of the period [4]. Specifically, in the year of 2017, China's foreign labor service cooperation dispatched 522,000 laborers of various types, and at the end of the year 979,000 laborers of all types worked outside the country. However, the labor service personnel dispatched by the Yunnan Province for foreign labor service only accounted for $2.17 \%$ of the national total.

\section{Total Export-Import Volume.}

According to data from the Department of Commerce of Yunnan Province, from January to December 2017, Yunnan's total imports were 80.659 billion yuan, up $45 \%$ year-on-year, and total exports were 77.207 billion yuan, a year-on-year increase of $1.5 \%$. The following figure shows the changes in the total import and export volume and growth rate of Yunnan Province from 2000 to 2016[5]. It can be seen from the figure. 1 that since the "One Belt and One Road" initiative was proposed in 2013, the import and export of Yunnan Province has increased, but the growth rate has shown a slowing trend.

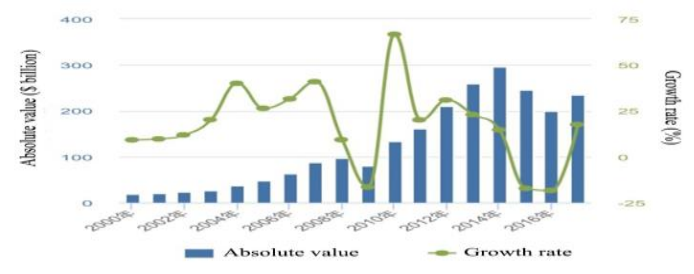

Fig.1 Total export-import volume of Yunnan Province in 2000-2016 Source: Yunnan Bureau of Statistics
On the other hand, from the perspective of participants in international operations, the state-owned enterprises are the mainstay, and the number of private enterprises has continued to increase. The state-owned enterprises, with their solid strength and ever-increasing experience in transnational operations, have been at the forefront of offshore investment and have played a pillar role in Yunnan's overseas investment. At the same time, Yunnan Province has a large number of SMEs participating in overseas investment. It is necessary not to hesitate to encourage and support private enterprises to actively go out and carry out international operations.

\section{THE CONSTRAINTS IN THE INTERNATIONALIZATION OF YUNNAN ENTERPRISSES}

\section{A. Enterprises Lack Talents and Management Experience}

At present, most Yunnan enterprises mainly achieve internationalization through foreign direct investment. The main model is limited to the establishment of wholly-owned enterprises through greenfield investment, and the establishment of joint ventures and cross-border mergers and acquisitions is rare [6]. This has also caused the talents shortage of Yunnan enterprises to achieve internationalization to a large extent. For a long time, the construction of talents in the western region, especially in Yunnan Province, has lags behind and cannot meet the needs of international talents. The shortage of talents has become a weakness that restricts the internationalization of enterprises in Yunnan Province.

In addition to the lack of talents, the enterprises' international business strategy is not clear and the positioning is not clear. The lack of a systematic strategic conception and operation model is also another major factor restricting the internationalization of Yunnan enterprises. At present, Yunnan enterprises have begun to internationalize their foreign direct investment in the countries along the "One Belt and One Road" around the country, but the internationalization of the operation is not satisfactory [7]. The reasons for this situation are not only the lack of talents mentioned above, but also the direct relationship between the lack of a clear strategic thinking and the positioning of the company, although it is involved in internationalization.

\section{B. The Relevant System is Still Incomplete and Construction of the International Large-Scale Corridor is Slow}

In the cooperation between Yunnan Province and neighboring countries, the policy is easy to "cut across the board" due to the imperfect of relevant laws and regulations. And as the level of convenience in customs clearance is still low and the level of opening is not high, the problem of inaction still stands out. In the border areas of Yunnan Province, the construction of trans-communities and bonded areas has slowed down[8]. There are related provincial direct management departments and central agencies, and the functions and affiliation of each department are not the same. In the implementation of specific operations, the authority of local governments is greatly constrained, and it is difficult to form a concerted effort to promote reforms along the border due to the overlapping of departmental functions. 
Yunnan Province has regional advantages and resource advantages, but it is neither along the river nor the coast, and it is facing the problem of high logistics costs [9]. Although Yunnan has been making great efforts to promote the construction of the international large-scale corridor for many years, it has made slow progress. The specific performance is as follows:

- The use of radiation in Kunming Changshui International Airport needs to be strengthened. The development of international routes is developing slowly which linking with Southeast Asia, South Asia, West Asia, Europe and the United States, and the airport layout with the combination of main and auxiliary airports has not yet formed; The lack of mature aviation freight forwarding companies seriously affects the export of flowers and specialty agricultural products of Yunnan Province.

- The lack of a land-water transport mechanism and the low level of international navigation channels are in urgent need of development, which seriously restricts the development of water transport and leads to high transportation costs.

- The lag in energy and internet infrastructure has severely constrained the development of energy foreign trade and e-commerce.

\section{Industrial Support is Insufficient and Foreign Investment Level is Still Low}

First of all, most of Yunnan's industries are at the bottom of the industrial chain, the development of dominant industries is insufficient, and there is a serious homogeneity of the industry with neighboring countries. As a result, Yunnan's foreign economy has not yet escaped the "channel economy". Import and export commodities are mainly transit-oriented. More than $90 \%$ of imported goods are exported to other provinces and more than $90 \%$ of the exported goods are from other provinces [10]. Therefore, even though Yunnan is the province with the largest number of ports and channels, it is the lowest average trade volume in the country. Secondly, the growth rate of overseas direct investment is faster, but the investment method is simple and the investment scope is limited. In recent years, Yunnan's overseas investment has grown at a faster rate, and the amount of investment has ranked at the forefront of the western region for many consecutive years. However, the newly-established investment in green space for enterprises is almost the only way for overseas investment in Yunnan. There are few cross-border M\&A and reorganization methods, the investment targets are mainly peripheral countries and regions, and the investment market is not wide enough. Investment is dominated by labor-intensive industries and resource development industries, traditional investment fields such as agriculture, mining, and power are still dominant, investment industries and fields are unevenly distributed, and irrational structures are more obvious [11]

\section{ANALYSIS OF OPPORTUNITIES AND ADVANTAGES}

\section{A. Policy Opportunity}

The national orientation of Yunnan in the One Belt One Road Strategy is: "Making use of Yunnan's regional advantages, advancing the construction of international transport corridors with neighboring countries, creating a new highland for economic cooperation in the Greater Mekong Subregion, and building a radiation center for South Asia and Southeast Asia"[12]. Yunnan province has supported by the nation's strategies and policy, such as the Western Development Strategy, Development Strategy of New Industrial District in Central Yunnan, and the Middle East Free Trade Zone, plus the current "One Belt and One Road" strategy. Supplemented by the exhibition centers of the China-South Asia Exposition and the Kunming Trade Fair, it can be seen that the company's international development trend and development environment are excellent.

On March 1, 2018, the "Administrative Measures on Overseas Investment of Enterprises" (Decree No. 11 of the National Development and Reform Commission) was implemented, which stipulated non-sensitive projects directly carried out by local enterprises, and projects with a Chinese investment of less than US\$300 million were just submitted to the provincial Development and Reform Commission for the record[13]. And it is not necessary to approve, record or report in the indirect investment. The streamlined administration and decentralization of power has given businesses a "green light" and further promoted the internationalization of foreign investment by Yunnan enterprises.

\section{B. Complementary Opportunities for Economic Development}

Although Yunnan and South Asia, Southeast Asia and ASEAN countries have certain similarities in their industrial structure, they are highly complementary in the modern development process. South Asia, Southeast Asia and ASEAN countries have advantages in petroleum, natural gas, metal ore, timber, rubber products, primary chemical products, agricultural products, tropical plants, etc., while Yunnan Province has advantages in chemical products, non-ferrous metals, electromechanical products, metal products, tobacco and Agricultural and sideline products, energy products, textiles and clothing [14]. Yunnan also has a certain industrial base. Except resource-based industries, Yunnan has a stronger industrial base than its neighbors in the manufacturing industry. Whether in the deep processing of mineral resources or in other manufacturing industries, neighboring countries may become the market of Yunnan enterprises [15].

\section{Location Advantages}

In the "One Belt and One Road" project, Yunnan province has a unique geographical advantage that can be connected to the Silk Road Economic Belt northward, to the 21st Century Maritime Silk Road southwards, and through the Yangtze River Economic Belt, can be connected to the "Yangtze River Delta" and "Pearl River Delta" economic circles eastwards[16]. In the "One Belt and One Road" strategy, Yunnan has the advantage of being a special "land transfer station" for imports and exports from inland regions to coastal countries and regions in the Indian Ocean. The transit of imported and exported goods 
to the countries and regions along the Indian Ocean after transit through Yunnan by land and sea, not only can save time and freight, but also provides stronger and safer transportation capacity and can more effectively avoid the risk of shipping in Malacca. At present, the development of airport construction in Yunnan Province is fast. It has opened routes with 14 national cities in Southeast Asia and 5 national cities in South Asia[17]. It is also building and upgrading the frequency of routes between Hong Kong, Macau, Taiwan, East Asia and West Asia, which has a great promotion effect for Yunnan Province to give full play to the advantage of the border market connection point.

\section{COUNTERMEASURES AND SUGGESTIONS FOR RESOLVING THE OVERCAPACITY IN YUNNAN PROVINCE THROUGH THE “ONE BELT ONE ROAD”}

Although there are many challenges in the process of internationalization of Yunnan enterprises, there are currently more opportunities. In the context of the "One Belt and One Road", the government should strengthen coordination with countries and regions along the route based on the principle of mutual benefit and win-win results, so that enterprises will be hindered by fewer non-economic factors in the process of internationalization [18]. In addition, enterprises in Yunnan Province should also enhance their own strengths and learn to gain a global perspective so that they can have more opportunities in the process of going global and going global. The relevant countermeasures and suggestions are put forward in the following aspects:

\section{A. Make full Use of Relevant Policies to Strengthen Coordination and Consultation Between Both Sides to Reduce risks and Resistance}

Since the 19th National Congress of the Communist Party of China, the state has successively introduced a series of policies and measures to encourage and support the accelerated development of the western region. We must in-depth study and make full use of relevant policies of the country to integrate various supportive policies such as comprehensive financial reforms along the border and development and opening up along the border, and intensify the effect of policy concentration[19]. Taking the functions of the platform, industrial cooperation and extension of the industrial chain as the core, it breaks down policy barriers and works together to enhance the driving power of various types of open platforms. At the same time, according to the actual situation in Yunnan Province, we must strive for more policies and support from the country.

In addition, the host country government should establish relevant bilateral rules to fully protect the legitimate rights and interests of corporate investors through the intergovernmental coordination and consultations [20]. It is also possible to provide enterprises with centralized services such as infrastructure, consulting, legal services through cooperation in the construction of trade parks and so on to reduce the difficulty of international business operations. The government can also establish a good image in the host country by providing official development assistance, and in this way it can promote the establishment of investment and product sales network for the host country, thereby deepening the internationalization of the company.

\section{B. Take the Advantage of Geographic Location and Speed up the Construction of the International Large-Scale Corridor}

Yunnan is an important radiation point for China to influence radiation to Southeast Asia, South Asia, West Asia and even Africa. It is also an important "node" of the "One Belt and One Road" and has an important geo-strategic position [21]. Therefore, in supporting the country's "One Belt and One Road", Yunnan should actively take the advantage of its geographical location, accelerate the construction of the westto-north international major corridor, and connect the mainland of China with the communications lines of Southeast Asia, South Asia, West Asia, and Africa. In particular, it is necessary to accelerate the construction of the third Eurasian Continental Bridge. The concept of constructing the third Eurasian Continental Bridge in Yunnan has been proposed a few years ago. It is mainly based on the coastal harbor group represented by Shenzhen Port as the starting point and Yunnan as the hub, via Myanmar, Bangladesh, India, Pakistan and Iran[22]. After entering Europe through Turkey, it finally arrived at the Port of Rotterdam in the Netherlands. Combining with the "One Belt and One Road", once the third Eurasian Continental Bridge is completed, it will accelerate the internationalization of Yunnan enterprises.

\section{Grasp Complementary AAdvantages to Form Community of Interests with the Host Country's Enterprises and Achieve mutual Benefits and Win-Win Results}

Yunnan has strong complementarities in economic development with countries in South Asia and Southeast Asia. In order to obtain more profits and even monopolize the market, many companies often enter the country in the form of whollyowned enterprises, or even if it is a joint venture with a host country enterprise, it only regards the other party as a production vassal and does not want to share its production technology and marketing network with it [23]. In general, the host government and residents will have a mental alert to foreign countries. If foreign investment is too strong, it will not only hinder the smooth implementation of the investment plan, but will also encounter a lot of trouble in the future business process. We should use complementary advantages to form a community of interests with the host country's enterprises, help break through a series of restrictions on foreign-funded enterprises, integrate into local culture faster, and gain irreplaceable advantages in developing markets and dealing with the government. In addition, the interests of the people in the host country must also be taken into consideration in terms of labor treatment, environmental protection and so on to obtain the support of the local people [24].

\section{Grasp the Advantages of National Policies to Strengthen the Cultivation of Internationalized talents and Improve the Level of Enterprises Themselves}

Since the Nineteenth National Congress, the state has continuously introduced policies that are conducive to Yunnan enterprises' internationalization under the "One Belt and One Road". In response to the shortage of talents, Yunnan Province should speed up the establishment of a mechanism that includes the training, introduction, and storage of international 
talents [25]. Targeted training of various types of talents is a good choice, in particular the increase in the cultivation and introduction of internationalized and integrated talents. There are some suggestions:

- Explore and establish a rational flow mechanism for export-oriented talents in the key areas such as government departments, open parks, key ports, and platform companies.

- Explore the establishment of institutional mechanisms conducive to innovation and entrepreneurship, actively build a platform for cooperation and exchange of think tanks for countries along the "One Belt and One Road" initiative, create "talent highlands," and attract a group of high-end talent with high reputation in China to gather in Yunnan.

- To create a favorable environment for the development of multinational talent resources, Yunnan enterprises still have some obstacles in integrating the "One Belt and One Road" and fully developing multinational talent resources. The legal environment, taxation system environment, and professional qualifications environment are all lacking, and further optimization and improvement are needed to provide solid personnel support for the development of internationalization strategies for Yunnan enterprises under the "One Belt and One Road".

- Yunnan enterprises should also accelerate the pace of innovation, enhance their overall strength, and create a good foundation for internationalization.

\section{CONCLUSION}

At present, the internationalization of Yunnan enterprises is relatively backward, and there is still ample room for development in foreign direct investment, foreign project contracting, and foreign labor cooperation. Yunnan enterprises should actively promote the internationalization process, make good use of policy opportunities, complementary opportunities for economic development, their own location and resource advantages to expand overseas, and seize the opportunity to overcome their talent and management deficiencies, so that enhance their international competitiveness.

\section{REFERENCES}

[1] Li Xia. A review of China's foreign investment in environmental risk and countermeasures[J]. China Population, Resources and Environment, 2015, 25(07):62-67.

[2] Duan Xiaomei, Huang Zhiliang. Challenges and countermeasures to further expand opening to the outside world in the new normal state[J]. Contemporary Economic Management, 2016, 38(06):49-55.

[3] Ren Jia, Liu Shixiang, Li Li. Accelerating the pace of "going out" to promote the development of Yunnan's open economy [J]. Yunnan Social Sciences, 2013 (02): 5-9.
[4] Guo Guangdong, Fan Bo. The Impact of Foreign Direct Investment on Domestic Employment in China: Taking Yunnan Province as an Example[J].Modern Management Science, 2012(11):65-67+91.

[5] Gao Yuan. Study on the Going-Out Strategy of Yunnan Enterprises [D]. Yunnan University, 2012.

[6] Yu Kexin. On the strategic vectors and countermeasures of western China's enterprises facing ASEAN internationalization: An example of Yunnan's resource-based enterprises and processing industries [J]. Exploration of Economic Issues, 2012(01):43-47+ 112

[7] Zhang Yongshuai. "One Belt and One Road" and Yunnan Foreign Economic Development [J]. Academic Exploration, 2016(07):12-18.

[8] Chen Fengmei, Liu Zhenzhong. Present Situation and Countermeasures of "Going Global" of Yunnan Enterprises under the Background of "One Belt and One Road" [J]. Chinese Market, 2017(22):78-79.

[9] Li Muyuan. Construction and Development Model of International Logistics Grand Channel[J]. China Ocean Shipping, 2018(02):52-53+9.

[10] He Ying, Zhang Xiaoxia. Study on the Integration of Yunnan into the Belt and Road Initiative [J]. Academic Exploration, 2016(01): 16-21.

[11] $\mathrm{Xu}$ Yunsong. Research on the Unbalanced Development of Regional Financial Development in Western China [D]. Central University of Finance and Economics, 2015

[12] Liu Dong, Zhu Li. Yunnan's advantages and positioning in the "One Belt and One Road" national strategy [J]. Shang, 2015(49):55.

[13] Zhu Xiongguan, Jiang Hao. The Analysis of the Advantages of Yunnan in the "One Belt and One Road" Strategy and Countermeasures[J] Journal of Chuxiong Teachers College, 2015, 30(04): 95-99.

[14] Wang Jia. Analysis of the policy effect of the completion of "ChinaASEAN Free Trade Area" on the impact of Yunnan residents' income gap[D].Yunnan University, 2015.

[15] Liu Wenshuai, Li Yazhong. New Ideas for the Development of Characteristic Industries in Yunnan Province that Integrate into the "One Belt and One Road" Strategy [J]. Theory of Studies, 2016(03):111-112.

[16] Yi Shui. Move to the front and compete for the Yangtze River Economic Belt [J]. Creation, 2014(10): 25-27.

[17] Huang Chen. Opportunities and Challenges of Foreign Trade Development in Yunnan Province under the Background of "One Belt and One Road" Strategy $[\mathrm{J}]$. Journal of Economic Research, 2017(35):150-151.

[18] Yunnan Edge Financial Comprehensive Reform Pilot Zone Sets Off Sina Finance

[19] Yang Zhihuang. Yunnan's Strategic Path of Opening up the New Realm of "One Belt and One Road" in South China[J]. Chinese Market, 2017(12):14-20

[20] Zhang Zhongyuan. The influence of host foreign direct investment restrictions on China's participation in the construction of global value chain[J].International Economic Cooperation, 2017(10):31-39.

[21] Zhu Xiongguan, Jiang Hao. The Analysis of the Advantages of Yunnan in the "One Belt and One Road" Strategy and Countermeasures[J]. Journal of Chuxiong Teachers College, 2015, 30(04): 95-99.

[22] Du Qiong,Zhou Longdi,Liang Ping.Construction of the Third Eurasian Continental Bridge and the Future Tendency of the Opening Economy Development in Western China[J].Theory Journal,2008(12):72-74.

[23] Li Qirong. The choice of the "going out" model for small and mediumsized enterprises in Yunnan Province under the bridgehead strategy [D] Wuhan University of Technology, 2012.

[24] Sheng Shengzhe. Six measures to deepen the "One Belt and One Road" cooperation to promote the internationalization of enterprises $[\mathrm{J}]$. China Economic Report, 2018 (03) :18-20.

[25] Ren Jia, Liu Shixiang, Li Li. Accelerating the pace of "going out" to promote the development of Yunnan's open economy $[\mathrm{J}]$. Yunnan Social Sciences, 2013 (02): 5-9. 